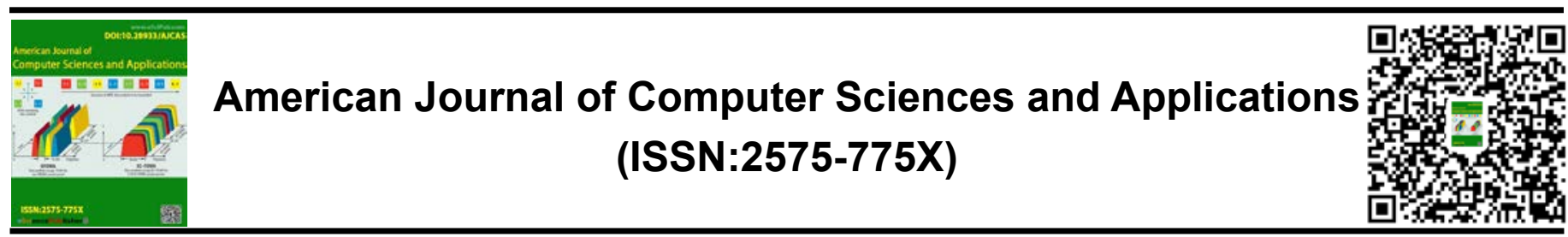

\title{
Unified transportation authenticated reservation system using online QR-code
}

\author{
Hussam Elbehiery ${ }^{1}$, and Ghada Abdelhady ${ }^{2}$ \\ ${ }^{1}$ Ahram Canadian University (ACU), ${ }^{2}$ October University for Modern Sciences and Arts (MSA)
}

\begin{abstract}
Public transit whether it is buses, trains, or metros can be particularly frustrating for passengers. Although public transit is typically cheaper and more green than traveling by a private vehicle, public transit may not be as comfortable, convenient, or as quick as a private vehicle, passengers will have to plan their schedules around the public transit timetables, and unforeseen circumstances may disrupt public transit operations. However, the drawbacks of public transportation is slowly being eliminated; public transit is starting to become more comfortable, districts are offering more amenities for passengers such as internet access, and districts are starting to improve service by offering more trips and express service. Designing a computerized system has been introduced in this research which is based on the Internet to remotely reserve all types of tickets for the most important and essential types of transportation in Egypt. The covered transportation types in the suggested system should be trusted like private Buses companies like GO Bus, Blue eyes, West Delta, and East Delta, Underground Metro, and Railway Trains network. By generating QR-Code which will be sent to the customer on his own mail using any connected device to Internet including all details of the ticket. Whenever the customer reserves the ticket, he can deal with in a hard copy or electronic version. The suggested reservation system depends on using the databases of National IDs and Visa Card. So, it will be very easy and helpful systems which will leads to save time and money too, and in future it will minimize dealing with the tickets' window in stations.

Keywords: Message Digest, QR-code, Reservation, Secure Hash Function and Transportation.

*Correspondence to Author:

Hussam Elbehiery

Ahram Canadian University (ACU)

How to cite this article:

Hussam Elbehiery and Ghada Abdelhady. Unified transportation authenticated reservation system using online QR-code. American Journal of Computer Sciences and Applications, 2018; 2:12.

\section{eScîPub}

eSciPub LLC, Houston, TX USA. Website: http://escipub.com/
\end{abstract}




\section{Introduction}

From passenger security and fleet management to assembly processes and delivery times, the transportation and logistics industry needs solutions that move its people and cargo safely and efficiently. Many businesses have already discovered the advantages of using mobile technologies; however, the unpredictable nature of fuel costs, rising labor rates, increased traffic and a changing regulatory environment, continue to make operations challenging. Transportation and logistics businesses around the globe are focused on maximizing supply chain efficiency in order to sustain profitability and viability. However, to reach this level of performance, they need to make end-to-end improvements. Complete visibility facilitates more effective, timely decisions and reduces delays through quicker detection of issues.

Mobile devices, such as radio frequency identification (RFID), barcode scanners, QR code scanners and mobile computers, have become a major influence in supply chain visibility and operations. Many transportation and logistics companies using these technologies today are reaching nearly 100 percent shipping and receiving accuracy, 99.5 percent inventory accuracy, 30 percent faster order processing and 30 percent reduction in labor costs.

With the advancement of technology, new software and devices are being developed to ease people's work. Waiting for ticket in long queues is a waste time process. Some people use the

Through the suggested system, web site to remotely reserve all types of ticket will be introduced. This site eases the task of buying travel tickets. People can buy their own travel tickets for the three types of transportation (Buses, Railway trains, Metro) using just a smart phone. The introduced system gives the availability of selecting seats based on the interest of the traveller. The essential point to be noted is that system uses only unified server for all the three modes of transportation [1]. The main objective of the suggested system is to provide sophisticated services to our society. That results in serving the community in saving money and time for people.

\section{Reservation system for tickets in Egypt}

\subsection{Railway trains reservation system}

In Egypt, it is a complex system so it is required to try to improve that system through the suggested system. The people must go to the railway stations and waiting for their turn in the queue to reserve tickets. May happen some mistakes about money or date...etc.

\subsection{Metro reservation system}

Metro is one of the most important means of transportation currently, especially in crowded cities, because of its ability to transport a large number of passengers at the same time without being affected or adversely affect traffic and walking in the main streets, this type of transportation is also environmentally friendly because it uses electric energy. The subway is one of the cheapest and fastest means of transport around the world. If you compare the value of the ticket with the other means, it is the cheapest and it saves a lot of time because it is not affected by traffic congestion, peak hours and the like. In Egypt the passengers have to go to the tickets' window to reserve a ticket. That may waste time so that is considering one of the disadvantages of Metro in Egypt. It is required to develop an advanced system in Egypt to overcome these obstacles.

\subsection{Buses reservation system}

In Egypt there are many buses and there is a public sector and a private sector. GO BUS is an Egyptian joint stock company working in the field of public transport under the supervision of the Ministry of Transport since 1998. These kinds of companies have fast and reliable facilities with distinctive seats for a comfortable, non-stop journey along the way. If a developed system can merge the reservation for these companies into a unified system that will be so effective.

\section{Suggest system outlines objectives}

Http://escipub.com/american-journal-of-computer-sciences-and-applications/ 
In deep search for the main causes of the problems facing the transportation system in Egypt in a whole point of view including the main three types (Buses, Railway trains, and Metro), it was obvious that there is a need to unified system for reservation of all types of tickets for all kinds of transportation in an easy manner. By using the introduced system via any computerized connect device. They have to visit the assigned site and search for the tickets they need through date and destination options. The available tickets will be displayed, and then only the approval for deducting from the bank account using the credit card without need to go anywhere saves their time.

After that the customer will receive a message that ensure his/her reservation and details of payment, time of trip and also receive QR- Code that will approve his/her to pass in the station. Also the passenger can choose the degree on the Railway trains/Metro through his/her reservation online. So the passengers have saved time and efforts. Also they saved money and reduced mistakes happened sometimes due to the crowdedness. The crowding and traffic will be indirectly minimized. The passenger will have a profile in the site which will include his/her interaction with the site and the trips that he/she had done.

\section{Suggest system structural design}

Figure 1 expresses the overall system design Data Flow Diagram (DFD). When passenger visits site, he/she has two options; he/she has an account on the system site or not. If he/she has an account he/she can simply login to his/her account and check it too. Then he/she can now go to the reservation process which contains Buses, Metro and Railway Trains, or go to his/her booked history which is leading to make the reservation. After that he/she can search for a ticket which contain all details he wants and making the reservation. Finally the site will send all information in QR-Code to the user's email. If he/she does not have an account he/she can create an account easily and enter the passenger's details. Then he/she can now go to the reservation process and do what he/she needs.

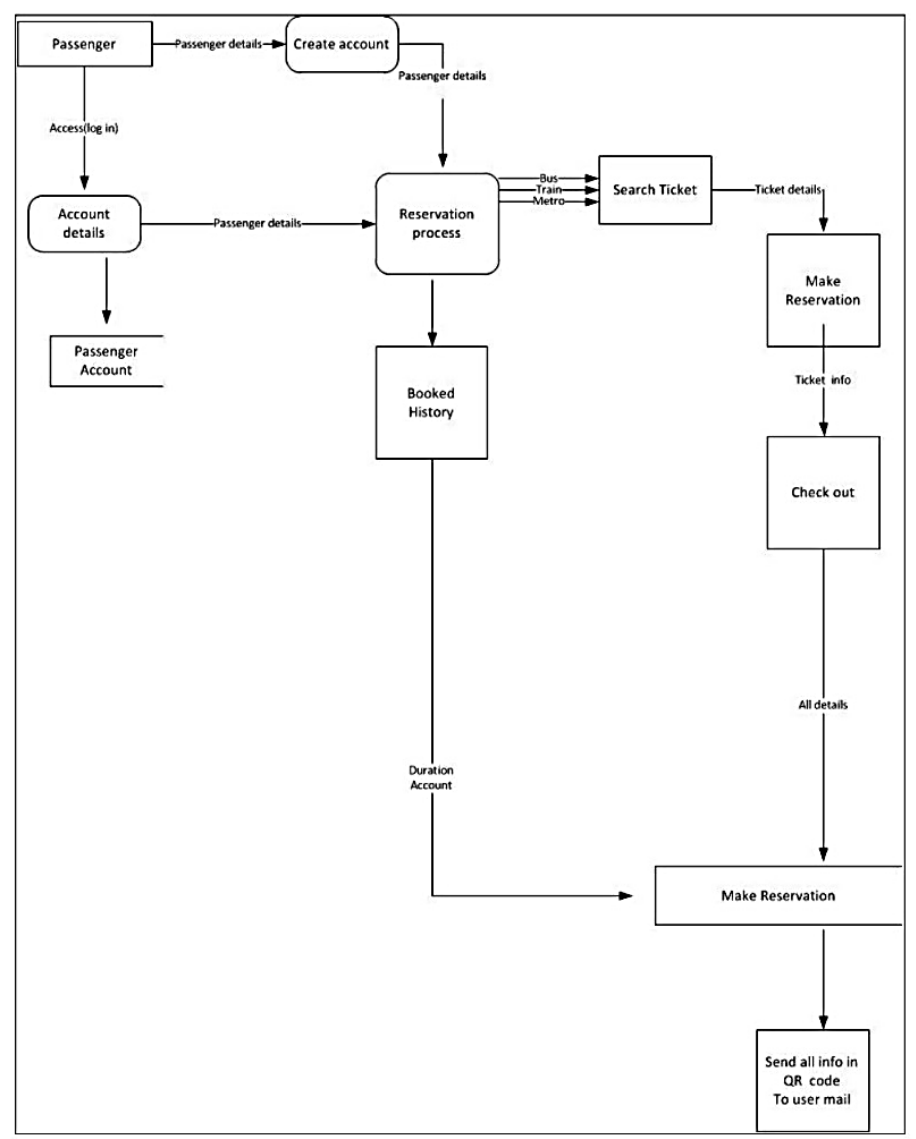


Figure 2 introduces a flowchart which simply again. So if he does not have an account, he/she describes the user login process to the can sign up to fill out the information then submit suggested system through his/her email and and going to login to enter the email and password. If it is valid login to the system will be password.

confirmed, and if it is not valid he/she can login

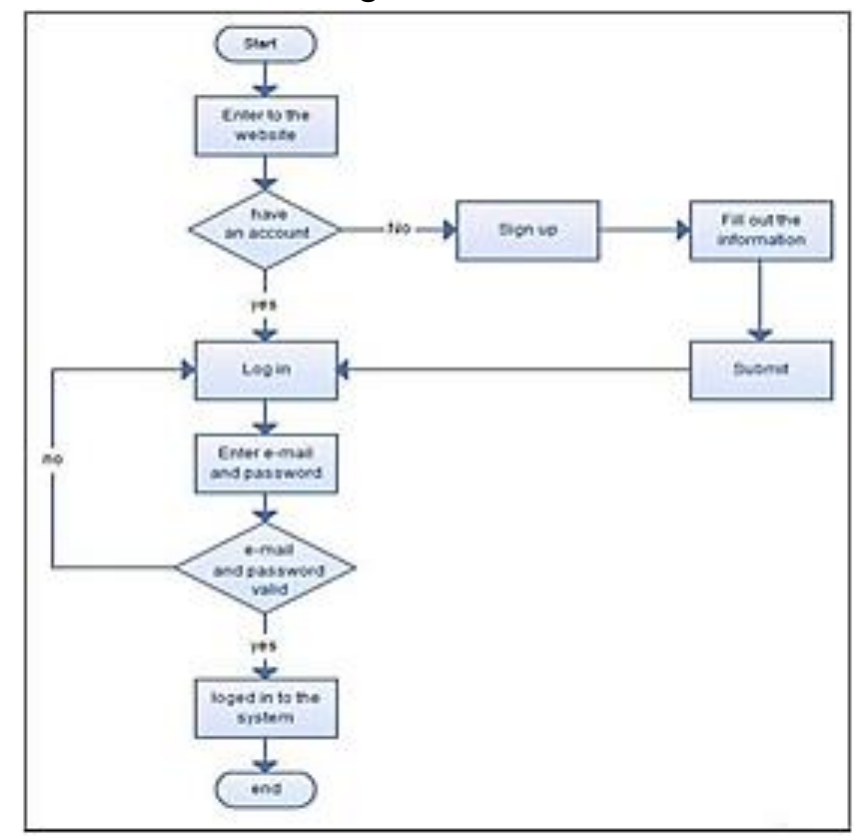

Figure 2 login processes for user/customer

As the passenger login to the website then information after that process and finishing the search the tickets that he/she wants and booking step. If not available he/she must search checking if it is available or not. If available, again for another ticket and so on. Figure 3 he/she confirms the booking then saves the shows the booking process and its details.

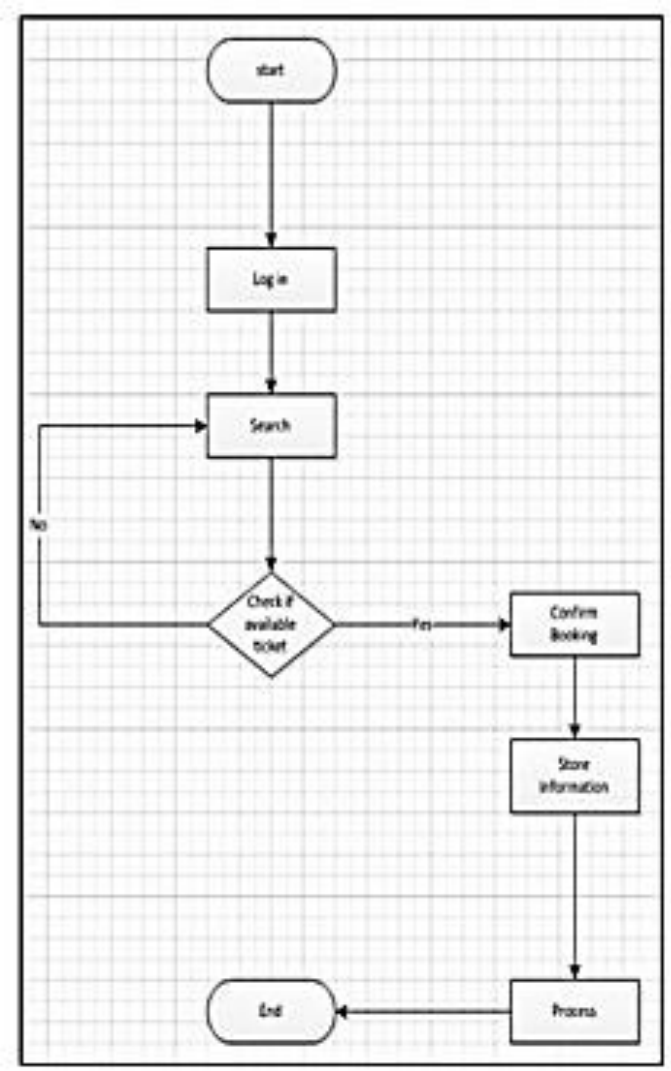

Figure 3 Booking processes for user/customer 


\section{Suggested system software tools}

\subsection{Database (MySQL)}

A database is a structured collection of data. Here are some typical examples of databases:

- An online store database that stores products, customer details and orders.

- A database for a web forum that stores members, forums, topics and posts.

- A database for a blog system, such as WordPress, that stores users, blog posts, categories, tags, and comments.

The software that manages databases is known as a DataBase Management System, or DBMS. MySQL is an example of a DBMS. Rather confusingly, DBMSs are often called databases too. Strictly speaking though, the database is the data itself, while the DBMS is the software that works with the database.

There are many different ways to organize data in a database, known as database models. One of the most popular is the relational model, which is what MySQL uses (along with PostgreSQL, Oracle, Microsoft SQL Server, and other common systems). Consequently, MySQL is known as a Relational DataBase Management System, or RDBMS.

Figure 4 shows how a database, the DBMS, and your website's code interact with each other.

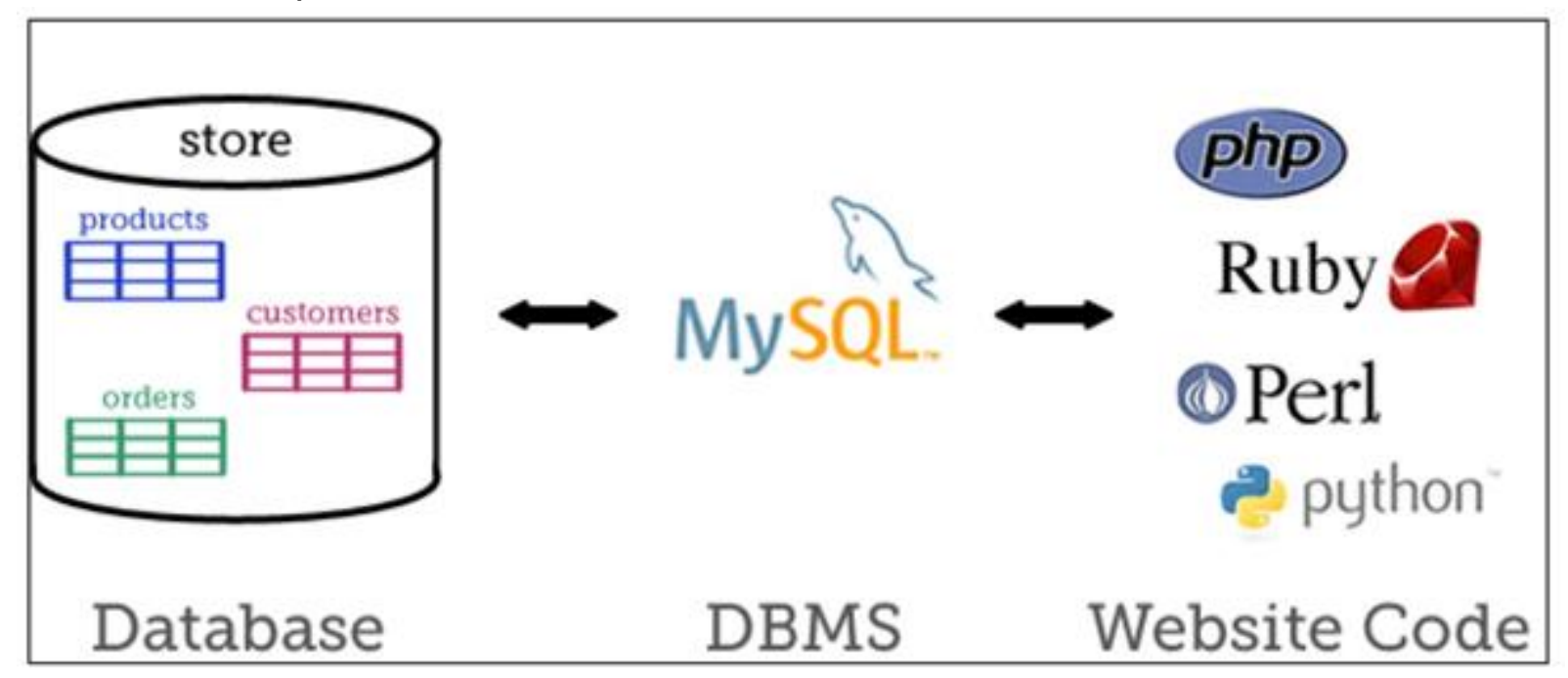

Figure 4 Database, DBMS, and the website's code interaction process

A database (left) is a collection of related data, managed by a DBMS such as MySQL (center). Web scripts (right) communicate with the DBMS in order to insert, update, delete and retrieve data in the database.

\subsection{Run-time environment}

JavaScript typically relies on a run-time environment (e.g., a Web browser) to provide objects and methods by which scripts can interact with the environment (e.g., a webpage DOM). It also relies on the run-time environment to provide the ability to include/import scripts (e.g., HTML <script> elements) [2], [3], [4] and [5]. The call stack shrinks and grows based on the function's needs. Upon function completion, when the stack is empty, JavaScript proceeds to the next message in the queue [5]. This is called the event loop, described as "run to completion" because each message is fully processed before the next message is considered. This means, for instance, that JavaScript can process a mouse click while waiting for a database query to return information [6], [7], [8], [9], [10] and [12].

\subsection{System Server PHP}

The server side has two PHP pages; Register, Login [13] and [14].

\section{- Registration page}

When the server receives a registration request from the client associated with Email, Password and the address, it will create a new record in the server data base in Users Info as the table showed in figure 5.

ID Email Password Address 


\begin{tabular}{|l|l|l|l|}
\hline ID & Email & Password & Address \\
\hline
\end{tabular}

\section{Figure 5 Table of Registration page}

\section{- Login Page}

When the user requests to login he will enter his email address and password, with the type of the Action he wants to do either backup or restore. The server will check the email and password if it is correct it will start a session for the user and store the user name and the ID of the user retrieved from the server database to use it as a path name to reach to backup files. If it is false the server will inform the client side that its password is wrong or he is not registered yet.

\subsection{QR-Code}

It is a type of 2D bar code that is used to provide easy access to information through a smartphone. In this process, known as mobile tagging, the smartphone's owner points the phone at a QR code and opens a barcode reader app which works in conjunction with the phone's camera. The reader interprets the code, which typically contains a call to action such as an invitation to download a mobile application, a link to view a video or an SMS message inviting the viewer to respond to a poll. The phone's owner can choose to act upon the call to action or click cancel and ignore the invitation [17].

\section{Suggested systems outcomes steps 6.1 Login Page}

When the user visits the website he/she will find this page shown in figure 6 which contains a login process if he/she already has an account on this website. If not, the user can login using Facebook, Twitter or Google.

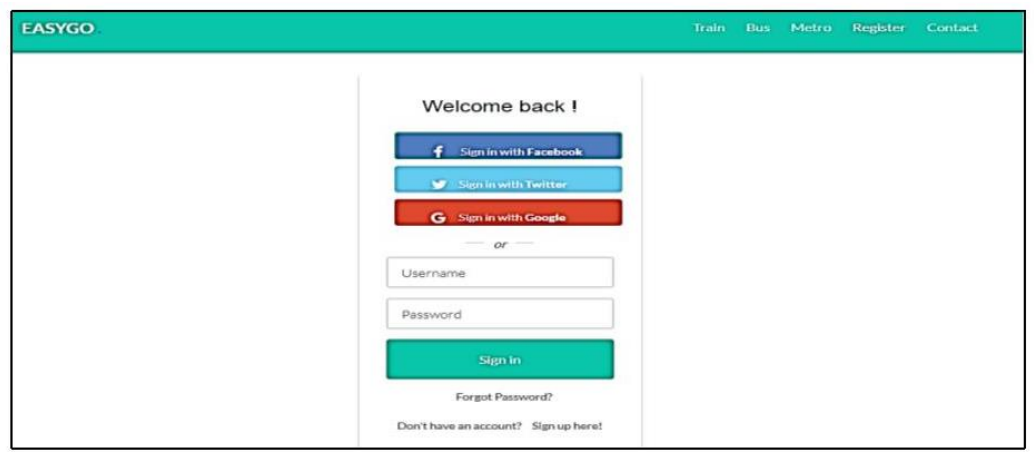

Figure 6 Login process Page

\subsection{Sign up Page}

If the user has not an account he can sign up to create an account by filling in all fields shown in figure 7 .

\subsection{Profile Page}

Figure 8 will be appeared after the Login or Sign up process. It shows the user's profile page that includes the user's information and also his/her interaction with the site.

\subsection{Contact Page}

Contact page is the last button in the navigation bar of the home page. The user will use this page if he/she wants to send a message to comment or suggest something or even to complain for any error happened. The contact page is shown in figure 9.

\subsection{Subscription Page}

In this page the site asks the user to enter his email to be the first to know the updates in the suggested services as shown in figure 10 [11].

\subsection{Bus, Railway Train, Metro reservation Page}

When the user enter to the train page from the navigation bar of the home page to search or buy a ticket. The user will find some fields like "from" "to" "date" "degree". Figure 11 shows the User Interface for the suggested system especially for Trains. 


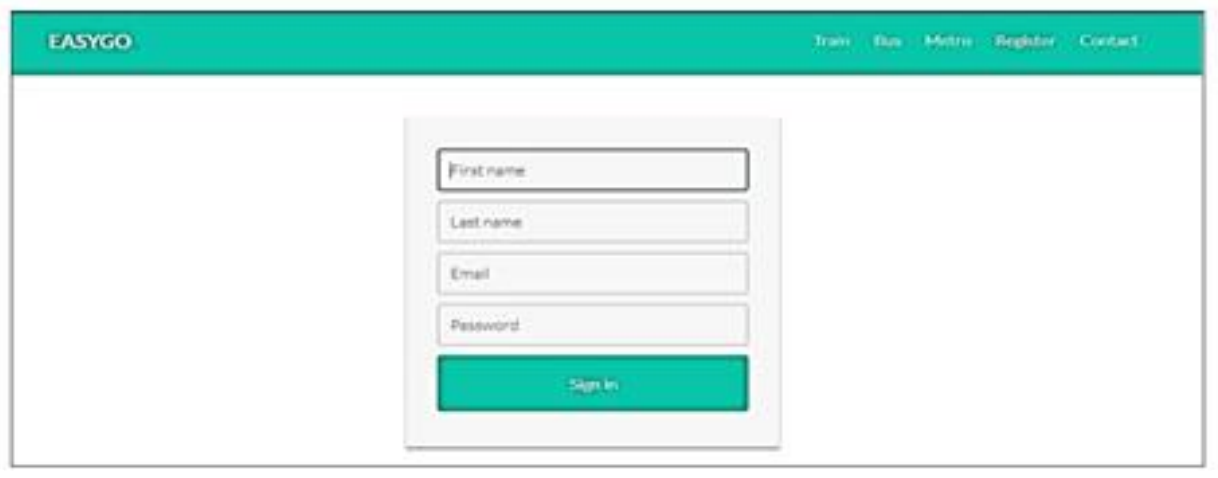

Figure 7 Sign up process page

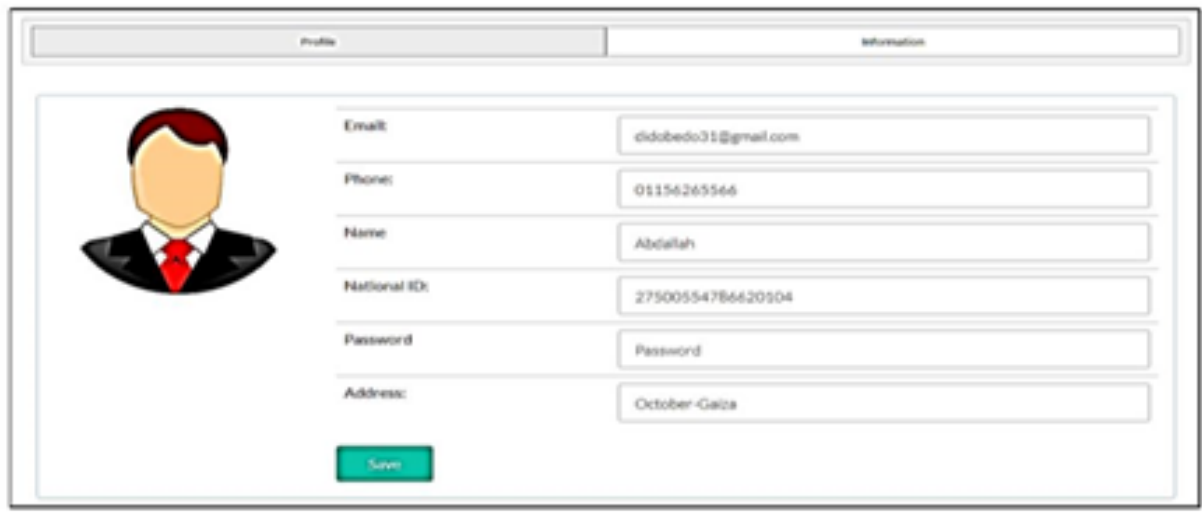

Figure 8 Profile Page

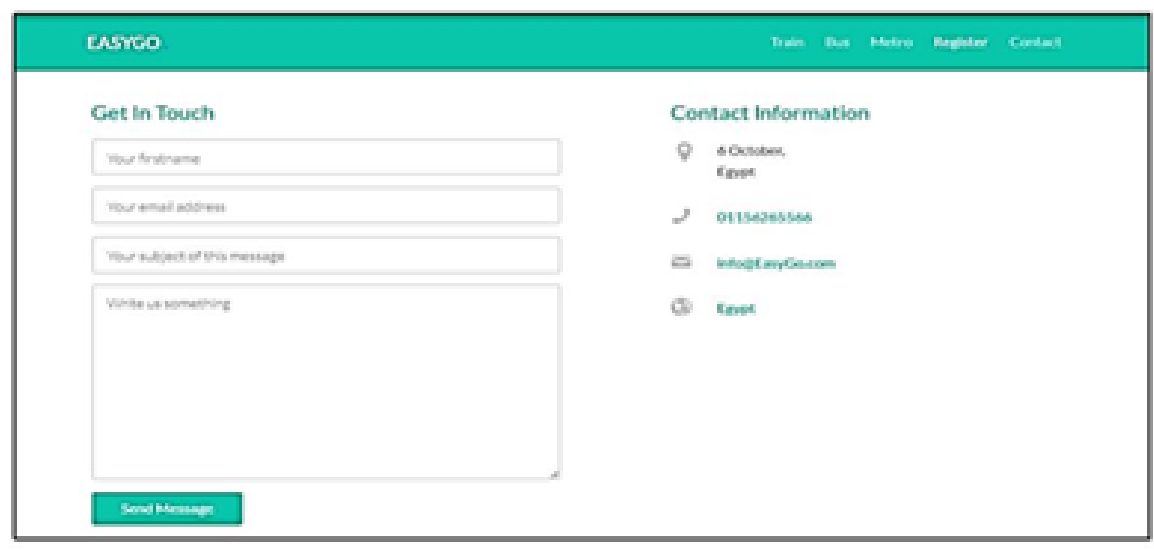

Figure 9 Contact Page

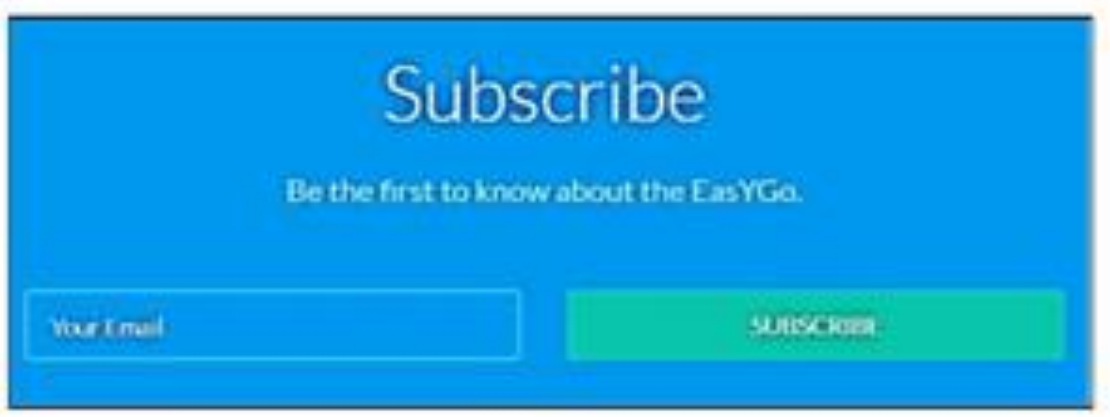

Figure 10 User Subscribe Page 


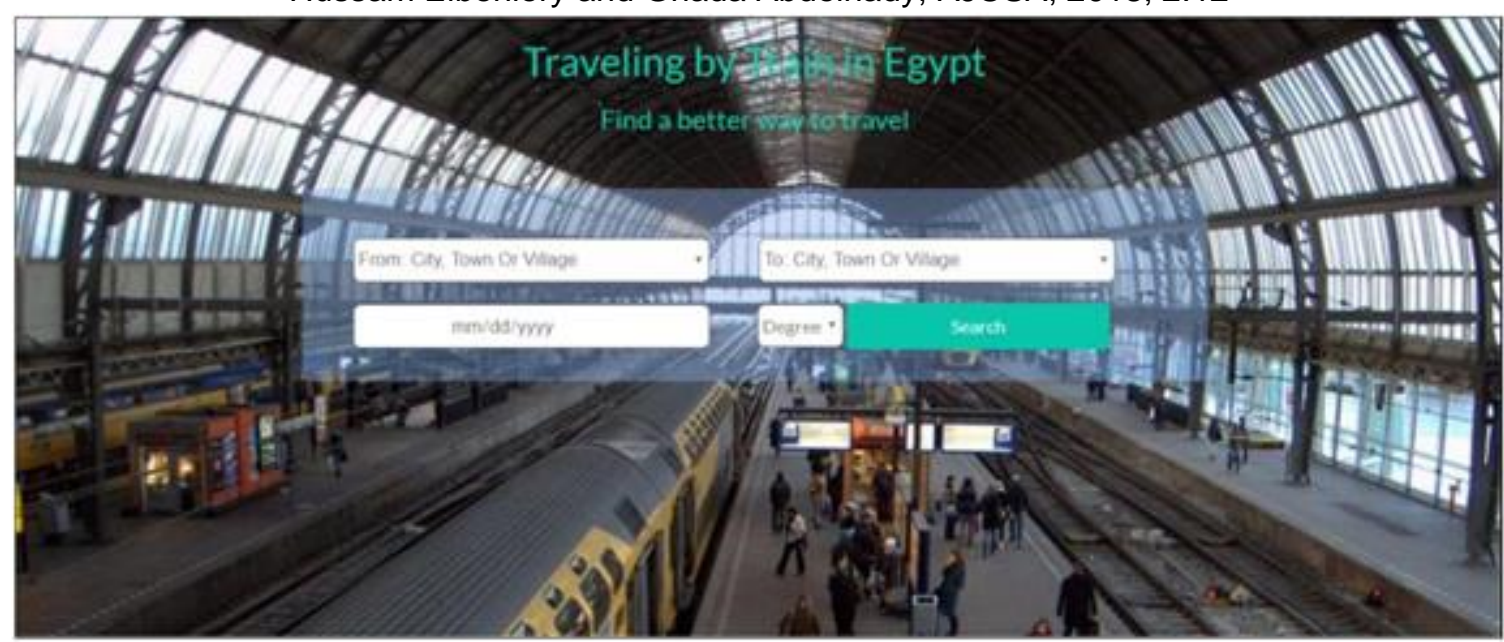

Figure 11 Railway Train reservation page

After searching process the user can select the results for searching and the information which suitable ticket to buy it. Figure 12 explains the will be used to issue the electronic ticket.

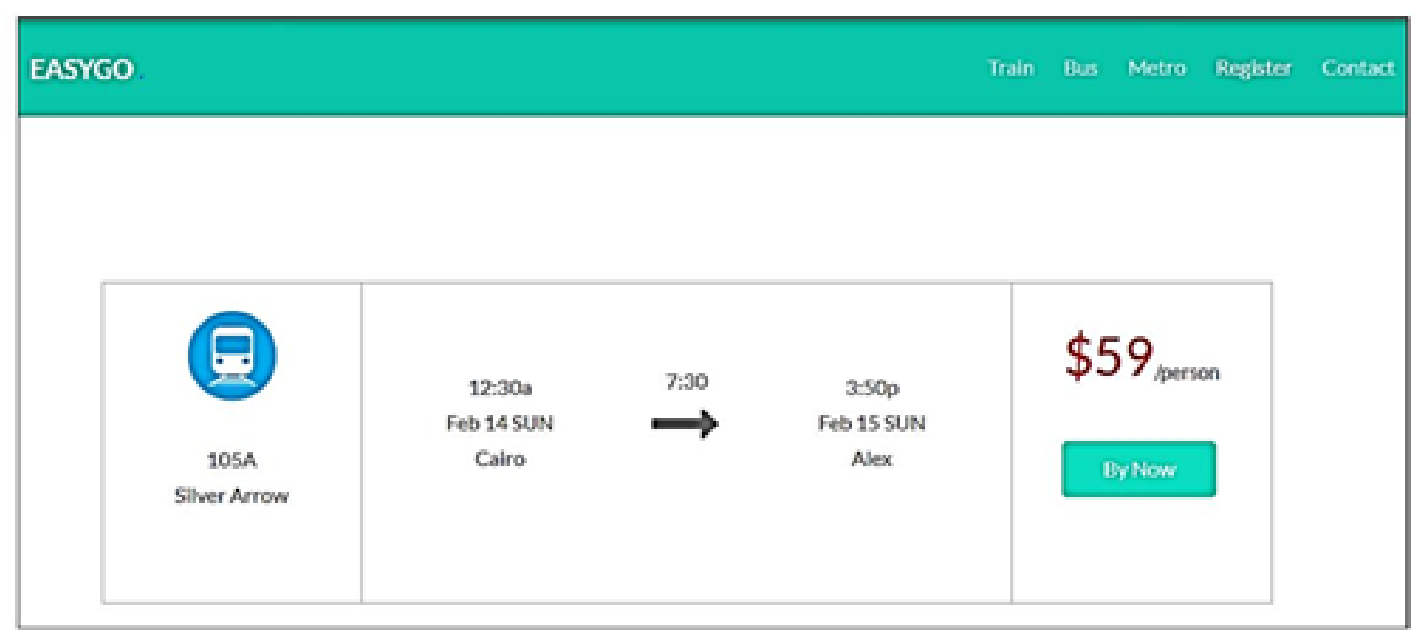

Figure 12 Searching ticket process

As shown in figure 12, once the user clicks on print or to send it to his/her registered email. the button "buy now" then the server will push Figure 13 shows the first step in ticket payment him into a new page to complete the buying which includes the user information also his process using his/her credit card. Then tickets credit card will be used.

will be issued and the user has two choices to

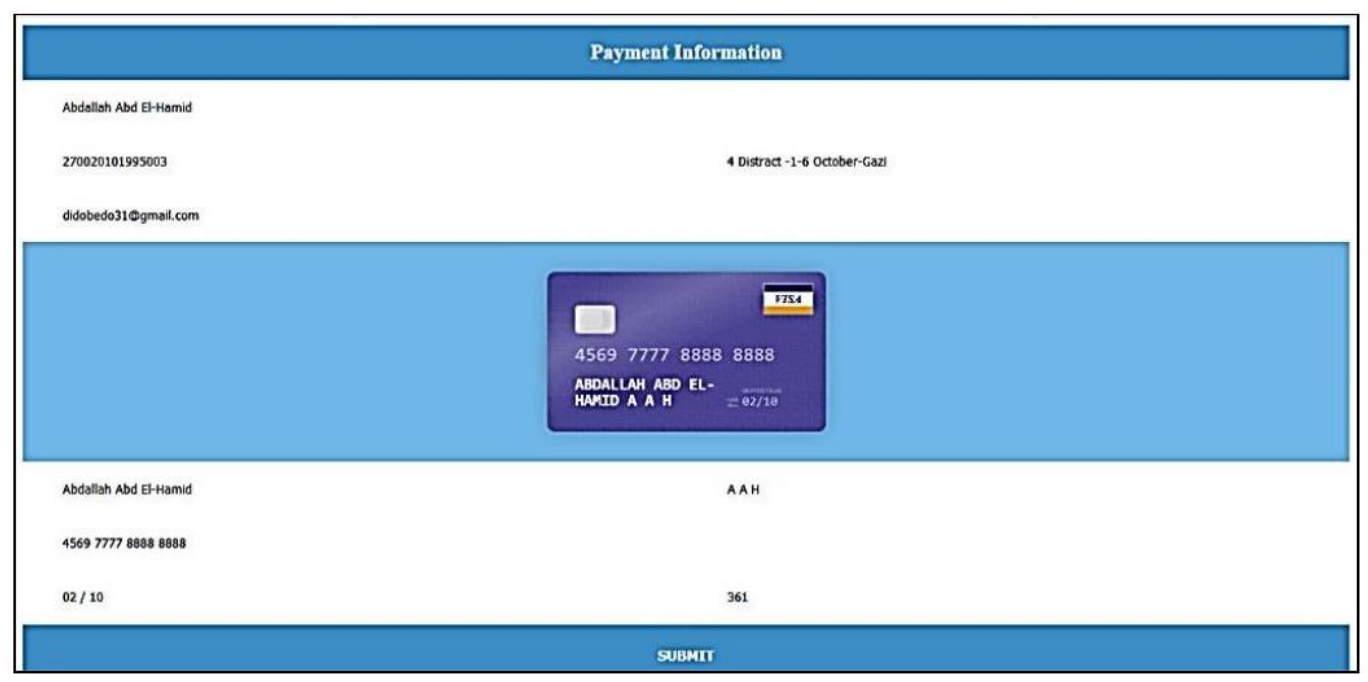

Figure 13 Payment information

Http://escipub.com/american-journal-of-computer-sciences-and-applications/ 
So if the user choose "send to email" the server user confirm his reservation and buying process will send message to the user's email which as shown in figure 14.

contain a ticket inside QR-Code to make the

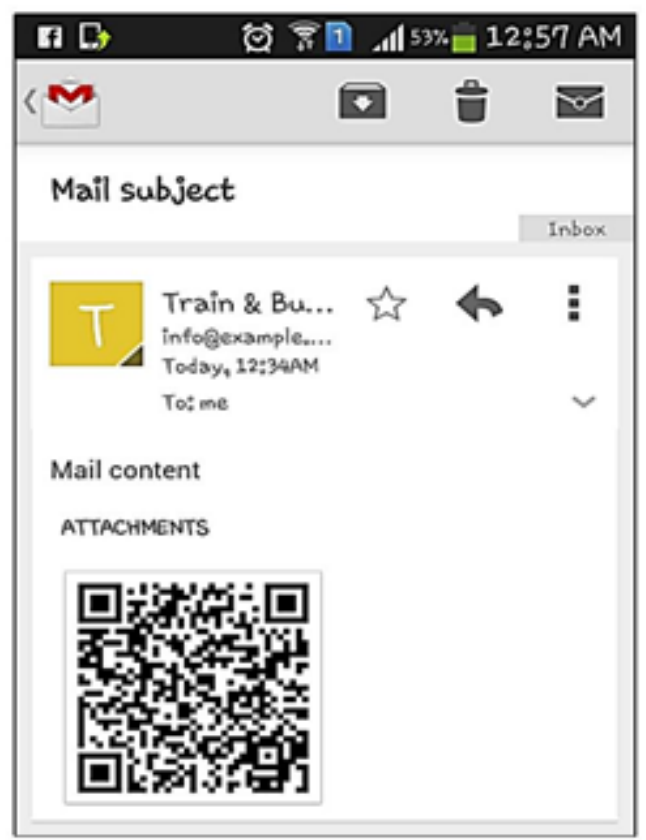

\section{Figure 14 Email received for the reserved ticket}

7. Security algorithms for the suggested Internet Standard RFC 1321. It is a 128-bit hash system

function. MD5 digests have been widely used in

Two algorithms have been used in the introduced system to make it more secure avoiding any hacking or attack on system site.

\subsection{Message Digest (MD)}

The MD family comprises of hash functions MD2, MD4, MD5 and MD6. It was adopted as the software world to provide assurance about integrity of transferred file. For example, file servers often provide a pre-computed MD5 checksum for the files, so that a user can compare the checksum of the downloaded file to it. Figure 15 describes the DFD of DM5 security algorithm.

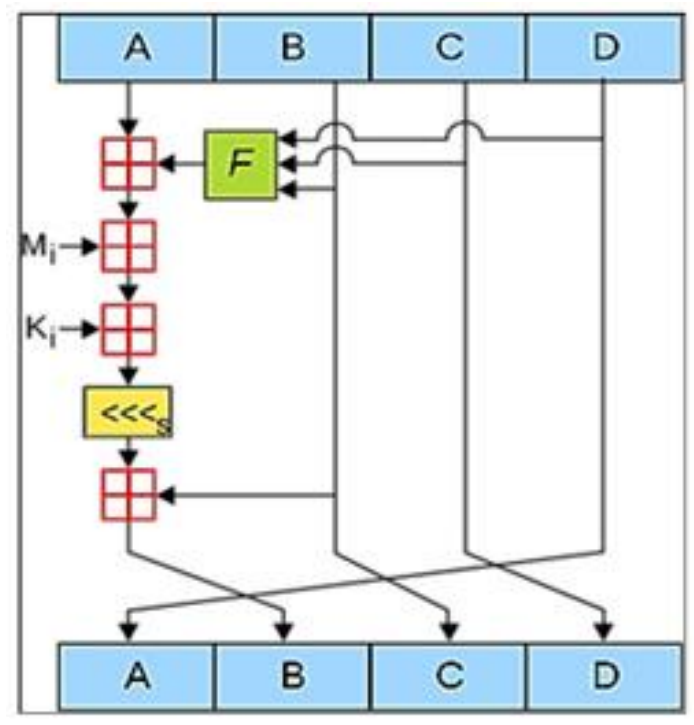

Figure 15 DFD of DM5

\subsection{Secure Hash Function (SHA)}

Family of SHA comprise of four SHA algorithms; SHA-0, SHA-1, SHA-2, and SHA-3. Though from same family, there are structurally different. The original version is SHA-0, a 160-bit hash function, was published by the National Institute of 
Standards and Technology (NIST) in 1993. It had few weaknesses and did not become very popular. Later in 1995, SHA-1 was designed to correct alleged weaknesses of SHA-0. SHA- 1 is the most widely used of the existing SHA hash functions. It is employed in several widely used applications and protocols including Secure Socket Layer (SSL) security. Though SHA-2 is a strong hash function. Though significantly different, its basic design is still follows design of SHA-1. Hence, NIST called for new competitive hash function designs. In October 2012, the NIST chose the Keccak algorithm as the new SHA-3 standard. Keccak offers many benefits, such as efficient performance and good resistance for attacks. Figure 16 describes the DFD of SHA1 security algorithm.

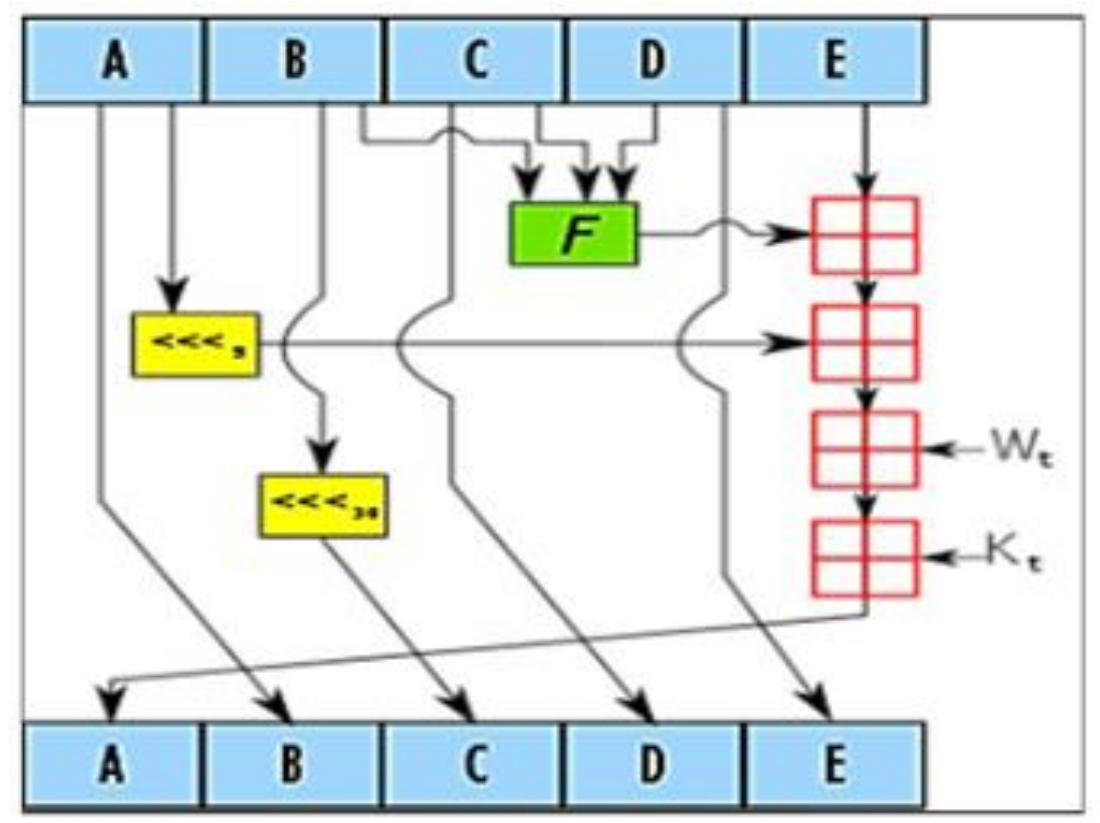

Figure 16 DFD of SHA1

\section{Conclusion}

The introduced system has been designed to remotely reserve all types of tickets for private buses, Underground Metro, all Railway Trains. Through a website via generating QR-Code sent to the user on his own email with the details of the ticket. The user can also deal with the ticket through his phone and also can print it. This will facilitate more features to the user and will serve our society. Co- operation between the different types of transportation will lead to help the society in improving transportation to various destinations. Recent technology has new various destinations and policy of use and retrieval especially in security of QR-codes to be more secure and efficient. Already the introduced system supported with wide database for all stations for the Busses, Railway trains and Metro, All these information is available for all people and foreigners to enhance tourism in Egypt.

\section{Acknowledgement}

This research was supported by Ahram Canadian University (ACU) and October University for Modern Sciences and Arts (MSA). We would like to thank our colleagues from Faculty of Computer Science and Information Technology and Faculty of Engineering who provided insight and expertise that greatly assisted the research.

\section{References}

1. David Cochran, "Twitter Bootstrap Web Development How-To-," Packt Publishing Limited, ISBN 10: 1849518823 ISBN 13: 9781849518826 , United Kingdom, 2012.

2. Jon duckett, "HTML and CSS: Design and Build Websites," Wrox a Wiley Brand Publishing, ISBN: 978-1-18-00818-8, USA, 2012.

3. Paul Wilton, and Jeremy Mcpeak, "Beginning JavaScript, "4th Edition, Wrox Publishing, ISBN10: 0470525932, ISBN-13: 978-0470525937, October 26, 2009.

4. Mikael Olsson, "JavaScript Quick Syntax Reference, "Publishing Apress, eBook ISBN: 978- 
1- 4302-6494-1, Softcover ISBN: 978-1-43026493-4, DOI: 10.1007/978-1-4302-6494-1, Sept 2015.

5. Thomas Valentine, Jonathan Reid, "JavaScript Programmer's Reference“, Publishing Apress, ISBN (1430246308, 9781430246305), Jun 2013.

6. Alexei White, "JavaScript Programmer's Reference," Publishing Wiley, ISBN (0470550503, 9780470550502), Jul 2009.

7. Ray Toal, and John David Dionisio, "The JavaScript Programming Language," publishing Jones \& Bartlett, ISBN (0763783064, 9780763783068), June 2009.

8. Jennifer Kyrnin, "Bootstrap in 24 Hours, Sams Teach Yourself," Sams Publishing, ISBN13: 9780672337048, November 2015.

9. David Cochran, and lan Whitley, "Bootstrap Site Blueprints," Packt Publishing, ISBN 13: 9871782164524), September, 2013.

10. Harmeet Singh, and Mehul Bhatt, "Learning Web Development with React and Bootstrap," Packt Publishing, ISBN 13: 987- 1786461513, December 2016.

11. Syed Fazle Rahman, "Jump Start Bootstrap: Get Up to Speed with Bootstrap in a Weekend", 1st
Edition, Sitepoint, ISBN-10: 0992279437, ISBN13: 978-0992279431, July 2014.

12. Nicholas C. Zakas, "Professional JavaScript for Web developers," Wiley Pub, (ISBN: 0764579088, 9780764579080), April 2005.

13. George Schlossnagle, "Advanced PHP Programming," Sams Publishing, ISBN (-13: 97811 0672325618), ISBN (-10: 0672325616), February 2004.

14. Adam Trachtenberg, and David Sklar, "PHP Cookbook," O'Reilly Media, ISBN (-10: 0596101015) ISBN (-13: 978-0596101015), July 2014.

15. Tony Northrup, and Chelsea Northrup, Photoshop CC Essentials for Photographers," Mason Press Publishing, ASIN (B01JD8Z52M), July 2016.

16. Adobe Creative Team, "Adobe Illustrator CC Classroom," Adobe Press ISBN10: 0321929497), ISBN13: 978-0321929495, July 2013.

17. Joe Waters, "QR Codes for Dummies," For Dummies, ISBN13: 978-1118337035, ISBN10: 1118337034 , June 2012.

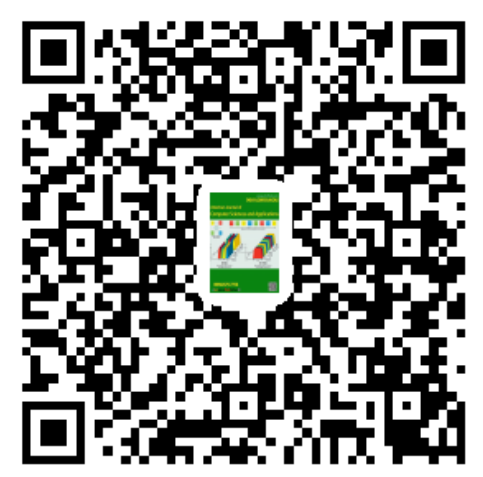

